\title{
Moleküler Dinamik Benzetim Yöntemi ile Isıtma İşlemi Sırasında Platin Metalinin Yapısal Gelişimi ve Erime Noktası Üzerine Atomlar-arası Potansiyel Etkisinin Araştırılması
}

\author{
Murat CELTEK $^{1 *}$, Unal DOMEKELI ${ }^{2}$, Sedat SENGUL ${ }^{2}$ \\ ${ }^{1}$ Trakya Üniversitesi, Eğitim Fakültesi Matematik ve Fen Bilgisi Eğitimi Bölümü, Edirne, Türkiye \\ ${ }^{2}$ Trakya Üniversitesi, Fen Fakültesi Fizik Bölümü, Edirne, Türkiye \\ (ORCID: 0000-0001-7737-0411) (ORCID: 0000-0003-1469-2602) (ORCID: 0000-0003-2690-9354)
}

\begin{abstract}
$\ddot{O} z$
$\mathrm{Bu}$ çalışmada, farklı atomlar-arası potansiyeller ve klasik moleküler dinamik (MD) benzetimleri kullanılarak, yüzey merkezli kübik $(f c c)$ yapıya sahip platin $(\mathrm{Pt})$ elementinin taban durumdan başlayıp erime noktasının hemen üzerindeki bir sıcaklık aralığındaki fiziksel özellikleri ve atomik yapısının devinimi detaylı bir şekilde incelenmiştir. Artan sıcaklığa bağlı olarak katı sistemin yapısal gelişimini analiz etmek ve erime noktasını belirlemek için çiftler dağılım fonksiyonu (PDF), enerji-sıcaklık (E-T), örgü parametresi-sıcaklık ( $a$-T), doğrusal termal genleşme katsayı-sıcaklık (CLTE-T) eğrileri ve çift analiz yöntemi gibi analiz yöntemleri kullanıldı. Tüm potansiyeller için MD benzetiminin sonuçlarının analizinden elde edilen veriler daha önce rapor edilen deneysel veya teorik verilerle karşılaştırılmış ve tartışılmıştır. Farklı atomlar-arası potansiyellerle elde edilen sonuçlar çoğunlukla birbirleri ile tutarlı olmasına rağmen, farklılık gösterdikleri noktalar da bulunmaktadır. Özellikle, sistemin erime noktasının belirlenmesi konusunda, her bir potansiyelin farklı erime sıcaklıkları ürettiği gözlenmiştir. Tüm potansiyel enerji fonksiyonlarında ortak olarak, artan sıcaklıkla birlikte $f c c$ yapıyı temsil eden 1421 bağlı çiftlerinin sayısı azalmış ve bu çiftlerin büyük bir bölümünün özellikle kusurlu icosahedra (deficos) ve kusurlu $f c c$ yapıyı temsil eden 1541 ve 1431 bağlı çiftlerine dönüştüğü görülmüştür. Pt elementi için burada ele alınan potansiyellerin bazıları düşük bazıları ise yüksek sıcaklık aralığındaki fiziksel özellikleri açıklamada başarılı olurken, Sheng ve arkadaşları tarafindan öne sürülen gömülü atom metot potansiyeli (EAM1) ve sık1-bağlı (TB) potansiyelinin saf Pt elementinin geniş sıcaklık ölçeğinde ele alınan tüm özelliklerini açıklamada diğerlerine göre daha başarılı olduğu görülmüştür.
\end{abstract}

Anahtar kelimeler: Moleküler Dinamik Benzetim, Çift Analizi, Atomlar-arası Potansiyel, Doğrusal Termal Genleşme Katsayısı, Erime Noktası, Platin.

\section{Investigation of the Effect of Interatomic Potential on the Structural Development and Melting Point of Platinum Metal During the Heating Process by Molecular Dynamic Simulation Method}

\begin{abstract}
In this study, the evolution of atomic structure and physical properties of platinum (Pt) element with face centered cubic $(f c c)$ structure starting from the ground state to high temperatures higher than its melting point have been comprehensively analyzed by using molecular dynamics (MD) simulation method in conjunction with five different interatomic many-body potentials. Analysis methods such as pair distribution function (PDF), energytemperature $(\mathrm{E}-\mathrm{T})$, lattice parameter-temperature $(a-\mathrm{T})$, coefficient of linear thermal expansion - temperature (CLTE-T) curves and pair analysis method have been used to analyze the structural development of the solid system depending on the increasing temperature and to determine the melting point. The data obtained from the analysis of the results of the MD simulation for all potentials have been compared and discussed with the previously reported experimental or theoretical data. Although the results obtained with different interatomic potentials are mostly consistent with each other, there are also points where they differ. In particular, in the
\end{abstract}

*Sorumlu Yazar: mceltek@trakya.edu.tr

Geliş Tarihi: 06.10.2018, Kabul Tarihi: 12.03.2019 
determination of the melting point of the system, it has been observed that each potential yields different melting temperatures. The number of 1421 bonded pairs representing the $f c c$ structure has been decreased with increasing temperature, and the most of them have transformed into 1541 and 1431 bonded pairs, which represent defect icosahedra (deficos) and defect $f c c$ structure. While some of the potentials considered in here for the Pt element have been successful in explaining the physical properties in the low temperature range and others in the high temperature range, results revealed that the embedded atom method potentials proposed by Sheng et al. (EAM1) and the tight-binding (TB) potentials successfully predict all properties discussed in wide temperature range.

Keywords: Molecular Dynamics Simulation, Pair Analysis, Interatomic Potential, Coefficient of Linear Thermal Expansion, Melting Point, Platinum.

\section{Giriş}

Atomik boyuttaki sistemlerin fiziksel özelliklerinin doğru ve hızlı bir şekilde açıklanmasını ve anlaşılmasını sağlayan en etkili araçlardan birisi benzetim teknikleridir. Moleküler dinamik (MD) benzetim yöntemi metaller, metalik alaşımlar, yarıiletkenler, polimerler, nano-malzemeler gibi birçok yüksek teknolojik malzemenin yapısal, dinamik ve termodinamik özelliklerini incelemek için yaygın olarak kullanılmaktadır [1-8]. MD benzetimde en önemli ve ana görevlerden biri, kuvvetlerin türetildiği uygun potansiyel fonksiyonların seçilmesidir. Sistemin özelliklerini araştırmak için seçilen potansiyel, sistemdeki atomların davranışlarını doğru bir şekilde modelleyemezse, MD benzetimden üretilen sonuçlar güvenilir olmaktan çıkar [9]. Atomlar - arası potansiyeller, atom sisteminin potansiyel enerjisinin hesaplanması için kullanılan matematiksel fonksiyonlar olup [10-12], kimya, moleküler fizik ve malzeme fiziğinde moleküler mekaniğin ve MD benzetimlerinin fiziksel temeli olarak ve bazen de malzemelerin kohezyon, 1sıl genleşme ve elastik özellikleri gibi etkilerle bağlantılı olarak yaygın bir şekilde kullanılmaktadır. Potansiyelleri seçerken dikkat edilmesi gereken unsurların başında, esneklik, doğruluk, yüksek sıcaklıklarda da doğru sonuçlar verebilme ve hesaplama hızı gelmektedir. Atomlararası potansiyelin seçimi, tamamen hedeflenen uygulama alanına bağlıdır; yani (neredeyse) "iyi” veya "kötü" potansiyel yoktur, belirli bir problem için uygun veya uygun olmayan potansiyel vardır. MD benzetimlerde kullanılan potansiyeller çiftler potansiyelleri ve çok cisim potansiyelleri olarak iki sınıfa ayrılır. Bunların arasında çiftler potansiyellerinin tipik örnekleri Lennard-Jones [13] ve Morse [14] potansiyelleridir. Bu potansiyeller, iyonik veya Van der Waals kristallerinin modellenmesinde başarılı sonuçlar vermesine ve yaygın olarak kullanılmasına rağmen, metaller için yetersiz kalmaktadır. Bu yetersizliği gidermek için, bağ elektronlarının çok sayıda kafes alanı üzerindeki güçlü yer değiştirme (delocalization) özelliklerini daha doğru ve güvenilir bir şekilde tanımlamak gerekir. Bunun için de sistemdeki etkileşmeleri daha doğru tanımlayabilen uzun menzilli çok cisim potansiyelleri tercih edilmelidir. Çok cisim potansiyelleri arasında gömülü atom metodu (Embedded Atom Method $(\mathrm{EAM})[15,16]$, geleneksel çiftler potansiyellerine ilk alternatiftir. Bu metot, halen MD benzetim yöntemlerinde metallerin fiziksel özelliklerini modellemek için tercih edilen en popüler seçimlerden biridir. Metalik sistemleri modellemek için aynı metoda dayanarak geliştirilen bir başka potansiyel ise, Finnis-Sinclair (FS) [17] potansiyelinin bir çeşidi olan Sutton-Chen (SC)[18, 19] potansiyelidir. Etkin ortam teorisi (Effective Medium Theory (EMT)) [20] potansiyeli de ayn1 aileye aittir ve bilgisayar benzetiminde, metallerdeki atom etkileşimlerinin temel fiziğini koruma/muhafaza etme ve hesaplamada harcanan çabayı azaltmak için yoğun olarak tercih edilmektedir. Sıkı-bağlı (Tight - binding (TB)) [21] veya diğer adıyla Rosato- Guillope - Legrand (RGL) [22] potansiyeli metaller ve metalik alaşımların fiziksel özelliklerini iyi tanımlayan ve bu yüzden de yaygın olarak kullanılan yar1-deneysel (semiempirical) çok cisim potansiyellerindendir. İkinci moment yaklaşımına dayanan TB potansiyeli, özellikle $d$-bant elektronlarının etkin rol oynadığı geçiş metallerinin fiziksel özelliklerini tanımlamak için uygundur.

$\mathrm{Bu}$ çalışmamızda platin (Pt) elementini, çok nadir bulunan kıymetli bir element ve çok geniş bir kullanım alanına sahip olması sebebiyle seçtik. Korozyona karşı dayanıklı olması, aşınma ve kararmaya karşı dirençli olmasının yanı sıra yüksek sıcaklıklara dayanabilmesi ve kimyasallara karşı yüksek direnç göstermesi bu elementin önemli özelliklerinden bazılarıdır. İşlenebilir ve sünme özelliğinden dolayı, diş hekimliğinde ve kuyumculukta; yüksek sıcaklıklara dayanabilmesinden dolayı, elektrik fırınlarının yapımında ve jet ve füze motorlarının ağız kaplamalarında kullanılmaktadır. Diğer yandan, otomobillerin egzoz sistemlerinde katalitik dönüştürücüler gibi uygulamalar için önemli bir katalizördür. Keşfedilmesinden bu yana sahip olduğu bu eşsiz özelliklerinden dolayı bilim insanlarının 
büyük ilgisini çekmektedir. Bilgisayar benzetimlerinde kullanmak üzere, Pt'nin fiziksel özelliklerini en doğru şekilde açıklayabilmek için pek çok potansiyel fonksiyonu bu elementin değişik fiziksel özelliklerine uydurularak (fit) parametrize edilmiştir. Çalışmamızda MD hesaplama hücresinde bulunan Pt atomları arasındaki etkileşmeleri tanımlamak için çok cisimli potansiyeller grubuna ait, Sheng ve arkadaşları tarafından geliştirilen EAM (EAM1) [23], Zhou ve arkadaşları tarafindan geliştirilen EAM (EAM2)[2], matematiksel formülü aynı fakat parametreleri farklı olan SC ve kuantum SC (Q-SC) ve son olarak Cleri ve Rosato tarafindan geliştirilen TB [21] potansiyellerini kullandık. Beş potansiyel kullanılarak MD benzetimden elde edilen sonuçların analizleri deneysel/teorik sonuçlarla karşılaştırmalı olarak bu çalışmanın ileriki bölümlerinde verilecektir.

\section{Atomlar-arası Çok Cisim Potansiyelleri}

Bilindiği üzere MD benzetimlerin güvenirliği, sistemdeki atomik etkileşimleri en iyi şekilde açıklayabilecek atomlar-arası potansiyele bağlıdır. Çiftler potansiyellerinin kolay yorumlanabilme ve hızlı hesaplama olanaklarına rağmen, küresel simetrik etkileşmelere uygulanması gibi bir takım sınırlama ve zorlamalarının olması araştırmacıları bu tür sınırlamaları olmayan çok cisim potansiyellerine yöneltmiştir [24]. Bu bölümde, çalışmamızda kullanılan çok cisim potansiyelleri hakkında kısaca bilgi verilecektir.

\subsection{Gömülü Atom Metot (EAM) Potansiyeli}

EAM modeline göre bir atomun toplam enerjisi elektrostatik itici (merkezi etkileşmeler) potansiyel enerjilerin toplamı ile atomun bulunduğu koordinattaki elektronik yük yoğunluğundan kaynaklanan gömme enerjisi terimlerinin toplamına eşittir. Bu tanıma göre $N$-atomlu bir sisteminin toplam enerjisi,

$$
E_{T}=\frac{1}{2} \sum_{i, j, i \neq j}^{N} \varphi_{i j}\left(r_{i j}\right)+\sum_{i}^{N} F_{i}\left(\rho_{i}\right)
$$

formunda verilir. Burada $\varphi_{i j}\left(r_{i j}\right)$, aralarında $r_{i j}$ mesafe olan $i$ ve $j$ atomlarının çiftler etkileşim enerjisi ve $F_{i}, \rho_{i}$ elektron yoğunluklu bölgeye $i$ atomunun gömülme enerjisidir. $\rho_{i}$ ifadesi ise, $i$ atomunu çevreleyen komşu atomların atomik yük yoğunluklarının toplamı şeklinde hesaplanır:

$$
\rho_{i}=\sum_{j, j \neq i} f_{j}\left(r_{i j}\right) .
$$

Burada $f_{j}\left(r_{i j}\right)$ atomik yük yoğunluk fonksiyonudur. EAM, içeriğindeki fonksiyonların matematiksel formunun ele alınan sisteme göre belirlenebilmesine ve bu fonksiyonların farklı yöntemlerle parametrizasyonuna imkân tanıyan esnek bir yöntem olduğundan, alan yazında pek çok farklı uyarlaması mevcuttur. Burada yer verilen formları için $[2,15,25,26]^{\text {' }}$ den daha ayrıntılı bilgi alınabilir. EAM1 potansiyel datası olarak, Sheng ve arkadaşları [23] tarafindan üretilen ve yazarın https://sites.google.com/site/eampotentials/Pt web adresinde paylaştığı çok cisim EAM potansiyeli işlenmiş datalarını kullandık. Diğer EAM potansiyeli ise, Zhou ve arkadaşları [2] tarafından geliştirilen EAM2 çok cisim potansiyelidir. EAM2 çiftler potansiyelinin formu [2];

$$
\varphi(r)=\frac{A \exp \left[-\alpha\left(r / r_{e}-1\right)\right]}{1+\left(r / r_{e}-\kappa\right)^{20}}-\frac{B \exp \left[-\beta\left(r / r_{e}-1\right)\right]}{1+\left(r / r_{e}-\lambda\right)^{20}}
$$

şeklinde verilir. Burada $A, B, \alpha$ ve $\beta$ ayarlanabilir parametrelerdir. $r$ iki atom arasındaki mesafeyi temsil eder. $r_{e}$ en yakın komşular arasındaki denge mesafesidir. $\kappa$ ve $\lambda$ ise iki ek parametredir. $\mathrm{Bu}$ formda elektron yoğunluk fonksiyonu;

$$
f(r)=\frac{f_{e} \exp \left[-\beta\left(r / r_{e}-1\right)\right]}{1+\left(r / r_{e}-\lambda\right)^{20}}
$$


şeklinde tanımlanır. Geniş bir elektron yoğunluğu aralığında çalışmak için gömme enerji fonksiyonlarının formları aşağıdaki şekilde ifade edilebilir.

$$
\begin{aligned}
& F(\rho)=\sum_{i=0}^{3} F_{n i}\left(\frac{\rho}{\rho_{n}}-1\right)^{i}, \quad \rho<\rho_{n}, \quad \rho_{n}=0.85 \rho_{e} \text {, } \\
& F(\rho)=\sum_{i=0}^{3} F_{i}\left(\frac{\rho}{\rho_{e}}-1\right)^{i}, \quad \rho_{n} \leq \rho<\rho_{0}, \quad \rho_{0}=1.15 \rho_{e}, \\
& F(\rho)=F_{e}\left[1-\ln \left(\frac{\rho}{\rho_{s}}\right)^{\eta}\right]\left(\frac{\rho}{\rho_{s}}\right)^{\eta}, \quad \rho_{0} \leq \rho .
\end{aligned}
$$

Bu çalışmada kullanılan EAM2 potansiyel parametreleri Tablo 1'de verilmektedir.

Tablo 1. Pt elementi için EAM2 çok cisim potansiyel parametreleri [2].

\begin{tabular}{cccccc}
\hline Metal & $\boldsymbol{r}_{\boldsymbol{e}}(\boldsymbol{\AA})$ & $\boldsymbol{f}_{\boldsymbol{e}}$ & $\boldsymbol{\rho}_{\boldsymbol{e}}$ & $\boldsymbol{\rho}_{\boldsymbol{s}}$ & $\boldsymbol{\alpha}$ \\
\hline \multirow{6}{*}{$\mathbf{P t}$} & 2.771916 & 2.336509 & 33.367564 & 35.205357 & 7.105782 \\
& $\boldsymbol{\beta}$ & $\boldsymbol{A}(\mathbf{e V})$ & $\boldsymbol{B}(\mathbf{e V})$ & $\boldsymbol{\kappa}$ & $\boldsymbol{\lambda}$ \\
\cline { 2 - 6 } & 3.789750 & 0.556398 & 0.696037 & 0.385255 & 0.770510 \\
& $\boldsymbol{F}_{\boldsymbol{n} \boldsymbol{0}}(\mathbf{e V})$ & $\boldsymbol{F}_{\boldsymbol{n} \boldsymbol{1}}(\mathbf{e V})$ & $\boldsymbol{F}_{\boldsymbol{n} \mathbf{2}}(\mathbf{e V})$ & $\boldsymbol{F}_{\boldsymbol{n} \mathbf{3}}(\mathbf{e V})$ & $\boldsymbol{F}_{\boldsymbol{0}}(\mathbf{e V})$ \\
\cline { 2 - 6 } & -1.455568 & -2.149952 & 0.528491 & 1.222875 & -4.17 \\
& $\boldsymbol{F}_{\boldsymbol{1}}(\mathbf{e V})$ & $\boldsymbol{F}_{\boldsymbol{2}}(\mathbf{e V})$ & $\boldsymbol{F}_{\boldsymbol{3}}(\mathbf{e V})$ & $\boldsymbol{\eta}$ & $\boldsymbol{F}_{\boldsymbol{e}}(\mathbf{e V})$ \\
\cline { 2 - 6 } & 0 & 3.010561 & -2.420128 & 1.450000 & -4.145597 \\
\hline
\end{tabular}

\subsection{Sutton-Chen (SC) ve Kuantum Sutton-Chen (Q-SC) Çok Cisim Potansiyelleri}

SC ve Q-SC çok cisim potansiyelleri [18, 19, 27, 28], matematiksel olarak aynı yapıya sahip olmalarına rağmen her iki potansiyelin parametrizasyon yöntemleri ve parametre değerleri bir birinden farklıdır. Bu modellere göre, $N$ atomlu bir kristalin toplam enerjisi;

$$
E_{T}=\sum_{i}^{N}\left[\frac{1}{2} \epsilon \sum_{j \neq i}^{N}\left(\frac{a}{r_{i j}}\right)^{n}-c \sqrt{\rho_{i}}\right]
$$

şeklinde verilir. Burada ilk terim atomlar - arası geri tepkimeyi açıklayan çiftler potansiyel olup, esas olarak çekirdek elektronlar arasındaki Pauli itmesinden kaynaklanır. İkinci terim ise gömme enerjisi olarak tanımlanır ve yerel yoğunluğun karekökü ile orantılı çekici terimdir. $r_{i j}, i$ ve $j$ atomları arasındaki mesafe, $c$ pozitif ve boyutsuz parametre ve $\epsilon$ enerji boyutuna sahip bir parametredir. $\rho$ gömme fonksiyonu $i$ atomunu çevreleyen komşu atomların atomik yük yoğunluklarının $i$ noktasındaki toplamı olarak

$$
\rho=\sum_{j \neq i}^{N} \rho\left(r_{i j}\right)=\sum_{j \neq i}^{N}\left(\frac{a}{r_{i j}}\right)^{m}
$$

şeklinde verilir. Burada $a$ kristalin örgü sabitidir. $n$ ve $m$ parametreleri pozitif tam sayılardır. Potansiyellerle ilgili daha ayrıntılı bilgi Ref [29-31]'den alınabilir. Bu çalışmada kullanılan SC ve QSC çok cisim potansiyel parametreleri Tablo 2'de verilmektedir.

Tablo 2. Pt elementi için SC ve Q-SC çok cisim potansiyel parametreleri[19].

\begin{tabular}{llllll} 
Potansiyel & $a(\AA)$ & $\epsilon\left(\mathbf{x 1 0}^{-2} \mathrm{eV}\right)$ & $n$ & $m$ & $c$ \\
\hline \hline
\end{tabular}




\begin{tabular}{cccccc}
\hline \hline SC & 3.9200 & 1.98330 & 10 & 8 & 34.408 \\
Q-SC & 3.9163 & 0.97894 & 11 & 7 & 71.336 \\
\hline
\end{tabular}

\subsection{Sıkı-Bağlı (TB) Çok Cisim Potansiyeli}

TB metodu, metal özelliklerinin büyük bir kısmının dıştaki $d$-elektronlarının yoğunluğundan türetilebileceği kabulüne dayanmaktadır. Kuantum mekanik kökene sahip ve çok-cisim toplamlarını içeren TB modelinde tek bir atomun toplam enerjisi iki parçaya ayrılabilir [21]:

$$
E_{C}^{i}=\sum_{i}\left(E_{R}^{i}+E_{B}^{i}\right)
$$

Born-Mayer iyon-iyon çiftler potansiyelleri tipinde olan birinci terim, $E_{R}^{i}$, sistemdeki itici etkileşmelerden sorumludur ve

$$
E_{R}^{i}=\sum_{j} A \exp \left[-p\left(\frac{r_{i j}}{r_{0}}-1\right)\right]
$$

olarak ifade edilir. Çekici etkileşmelerden sorumlu olan ikinci terim ise EAM'daki $F(\rho)$ gömme fonksiyonunun görevini üstlenmektedir:

$$
E_{B}^{i}=\left\{\sum_{j} \xi^{2} \exp \left[-2 q\left(\frac{r_{i j}}{r_{0}}-1\right)\right]\right\}^{1 / 2}
$$

Burada $r_{i j}, i$ ve $j$ atomları arasındaki mesafeyi ve $r_{o}$ ise en yakın komşu mesafesini temsil eder. $A, p, \zeta$, ve $q$ parametreleri, elementlerin fiziksel özelliklerine bağl1 model parametreleridir. Potansiyel parametreleri hakkında daha ayrıntılı bilgi [21, 32-35] referanslarından bulunabilir. Pt elementi için MD benzetimde kullanılan ve Ref [21]'den alınan TB çok cisim potansiyel parametreleri Tablo 3'de verilmektedir.

Tablo 3. Pt elementi için TB çok cisim potansiyel parametreleri [21].

\begin{tabular}{cccccc}
\hline Potansiyel & $\boldsymbol{A}(\boldsymbol{e} \boldsymbol{V})$ & $\boldsymbol{\xi}(\boldsymbol{e V})$ & $\boldsymbol{p}$ & $\boldsymbol{q}$ & $\boldsymbol{r}_{\mathbf{0}}(\boldsymbol{\AA})$ \\
\hline \hline TB & 0.2975 & 2.695 & 10.612 & 4.004 & $2.77^{*}$ \\
\hline
\end{tabular}

*Ref [36]'den alındi.

\section{Moleküler Dinamik (MD) Benzetim Metodu}

Pt elementinin 1sıtma sürecinde bazı fiziksel özelliklerinin sıcaklığa bağlı değişiminin MD benzetim çalışmaları için Smith ve arkadaşları [37] tarafından geliştirilen ve açık kaynak olarak verilen DL_POLY 2.0 benzetim paket programı kullanılmıştır. Isıtma işlemi, sıfır basınç altında $(\mathrm{P}=0) \mathrm{NPT}$ (sabit parçacık sayısı, basınç ve sıcaklık) topluluğu ile gerçekleştirildi. MD benzetimlerinde periyodik sınır koşulları, başlangıçta ideal $f c c$ yapısında düzenlenen $13500(15 \times 15 \times 15 \times 4) \mathrm{Pt}$ atomu içeren kübik bir MD hesaplama hücresine her üç doğrultuda uygulandi. Benzetim boyunca sıcaklığı ve basıncı kontrol etmek için Nosé-Hoover termostat ve barostatı kullanıldı [38]. Newton hareket denklemleri, toplam enerjide oluşacak dalgalanmaları azaltmak için yeterli derecede küçük zaman adımıyla ( $2 \mathrm{fs}$ ) ve Leapfrog Verlet algoritması kullanılarak çözüldü. Beş farklı potansiyel için $\mathrm{T}=0 \mathrm{~K}$ 'deki başlangıç yapısı önce $300 \mathrm{~K}$ 'e 1sıttlıp daha sonra $2 \mathrm{~K}$ sicaklığa soğutularak Pt atomlarının ideal örgü noktalarına yerleşmeleri sağlandı. Daha sonra sistem, bu sıcaklıktan başlayarak $50 \mathrm{~K}$ sıcaklık artışıyla, her sıcaklıkta 40,000 MD adımı sistemi dengeye getirmek için ve 10,000 MD adımı istatistik hesaplar için olmak üzere toplamda 50,000 adımlı MD benzetimleri ile $3000 \mathrm{~K}$ 'e 1sitıldı. Bu şekilde yürütülen benzetimlerimizde 
1sıtma oranı, $\gamma=0.5 \mathrm{~K} / \mathrm{ps}$ 'ye karşı1lık gelmektedir. Sistemin birinci-derece faz geçişi yaptığı bölgede 10 K’ lik sıcaklık artışı kullanılarak erime sıcaklığının belirlenmesindeki hata miktarı azaltılmıştır.

\section{Bulgular}

\subsection{Kohesif Enerji, Örgü Parametresi ve Doğrusal Termal Genleşme Katsayısı}

Şekil 1'de beş potansiyel için sistemin kohesif enerjilerinin sıcaklığa bağlı değişimi (E-T) gösterilmektedir. Artan sıcaklıkla birlikte bütün potansiyeller için E-T eğrilerinin neredeyse doğrusal olarak değiştiği ve E-T eğrilerinde her potansiyel için farklı sicaklık değerlerinde ani ve keskin bir değişimin olduğu görülmektedir. Bu durum sistemin kristal yapıdan sıvı yapıya geçiş yaptığının açık bir göstergesidir. Sıcaklık artışı ile yüksek sıcaklıklarda sistemin kohesif enerji değişiminde görülen süreksizlik sıvı faza geçiş noktasına karşılık gelmektedir. Burada verilen beş potansiyel kullanılarak sıfır basınç altında çalışılan sistemin erime sıcaklıkları (sıvı olma sıcaklıkları) EAM1 için $\mathrm{T}_{\mathrm{m}}=2050 \pm 5 \mathrm{~K}$ $\left(\mathrm{T}_{\mathrm{l}}=2060 \pm 5 \mathrm{~K}\right), \mathrm{EAM} 2$ için $\mathrm{T}_{\mathrm{m}}=1810 \pm 5 \mathrm{~K}\left(\mathrm{~T}_{\mathrm{l}}=1820 \pm 5 \mathrm{~K}\right), \mathrm{Q}-\mathrm{SC}$ için $\mathrm{T}_{\mathrm{m}}=2410 \pm 5 \mathrm{~K}\left(\mathrm{~T}_{\mathrm{l}}=2420 \pm 5 \mathrm{~K}\right)$, $\mathrm{SC}$ için $\mathrm{T}_{\mathrm{m}}=1670 \pm 5 \mathrm{~K}\left(\mathrm{~T}_{\mathrm{l}}=1680 \pm 5 \mathrm{~K}\right)$ ve $\mathrm{TB}$ için ise $\mathrm{T}_{\mathrm{m}}=2000 \pm 5 \mathrm{~K}\left(\mathrm{~T}_{\mathrm{l}}=2010 \pm 5 \mathrm{~K}\right)$ olarak belirlenmiştir. Deneysel erime sıcaklığ $\mathrm{T}_{\mathrm{m}}=2045 \mathrm{~K}$ [36] ile karşılaştıııldığında $\mathrm{MD}$ benzetim sonuçlarından belirlenen bu değerler, deneyselden EAM1 için \% 0.24, EAM2 için \% -11.49, Q-SC için $\%$ 17.85, SC için \%-18.34 ve TB için ise \%-2.20 oranında bir sapma olduğu görülmektedir. Uyguladığımız benzetim prosedürüne göre EAM1 ve TB çok cisim potansiyellerinin deneysel erime sıcaklık değerine çok yakın değerler ürettiği söylenebilir. MD benzetim sonuçlarının deneyselden farklı çıkmasına veya sapmasına, MD hesaplama hücresinde kullanılan parçacık sayısının yeterli olmaması ve başlangıçta kurulan MD hücresinin yapısal kusurlar içermemesi gibi nedenler gösterilebilir.

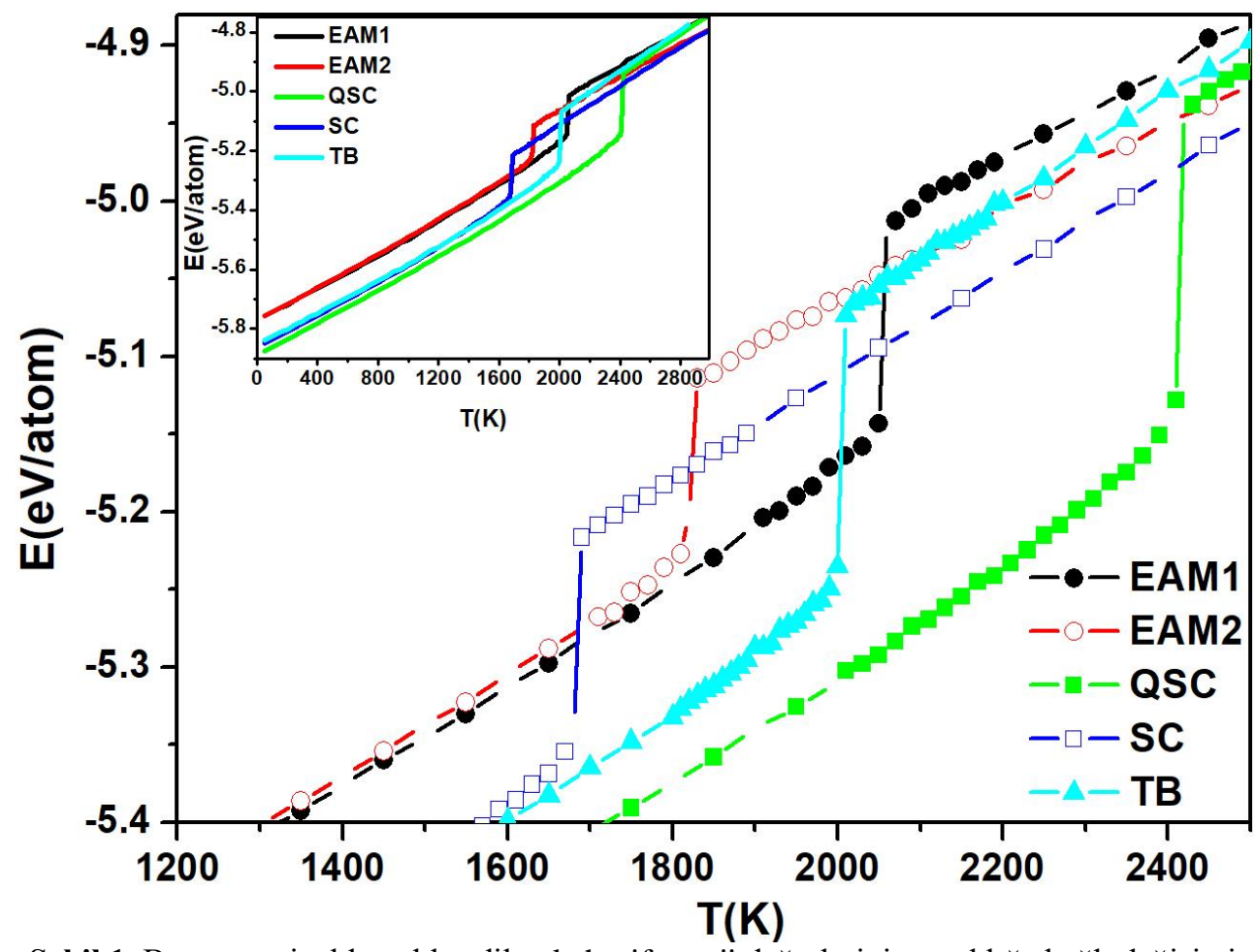

Şekil 1. Beş potansiyelden elde edilen kohesif enerji değerlerinin sıcaklığa bağlı değişimi.

Diğer yandan her bir potansiyel için $0 \mathrm{~K}$ 'de Berendsen termostatı kullanılarak sistemin kohesif enerji ve $300 \mathrm{~K}$ 'de örgü parametre değerleri MD benzetim çıktı dosyaları analiz edilerek hesaplandı. Bu analizlere göre, EAM1, EAM2, Q-SC, SC ve TB çok cisim potansiyelleri ile belirlenen örgü parametreleri ve kohesif enerji değerleri surasiyla, $\mathrm{a}=3.92 \AA\left(\mathrm{E}_{\mathrm{c}}=5.771 \mathrm{eV}\right), \mathrm{a}=3.93 \AA\left(\mathrm{E}_{\mathrm{c}}=5.770 \mathrm{eV}\right)$, $\mathrm{a}=3.92 \AA\left(\mathrm{E}_{\mathrm{c}}=5.887 \mathrm{eV}\right), \mathrm{a}=3.93 \AA\left(\mathrm{E}_{\mathrm{c}}=5.848 \mathrm{eV}\right)$ ve $\mathrm{a}=3.93 \AA\left(\mathrm{E}_{\mathrm{c}}=5.853 \mathrm{eV}\right)$ şeklindedir. Daha önce alanyazında rapor edilen deneysel örgü parametresi $a=3.92 \AA$ [36] ve kohesif enerji $\mathrm{E}_{\mathrm{c}}=5.84 \mathrm{eV}$ [36] ile karşılaştırıldığında, bulgularımız ile deneysel değerler arasındaki sapma miktarı EAM1'de \% 0.0 (\% - 
1.18), EAM2 'de \% 0.26 (\% -1.199), Q-SC' de \% 0.0 (\% 0.80), SC ‘ de \% 0.26 (\% 0.14) ve TB 'de ise $\% 0.26$ (\% 0.22) 'dir. Bütün potansiyellerden elde edilen değerler, birbirleriyle ve deneysel değerlerle tutarlı görülmektedir. Ayrıca, sonuçlarımızın daha önce bildirilen deneysel ve MD benzetim [2, 21, 23, 27] sonuçlarıyla da büyük ölçüde uyumlu olduğu görülmektedir. Bütün olarak bakıldığında benzetimde kullanılan parçacık sayısına, sıcaklığı kontrol altında tutmak için tercih edilen termostat seçimine ve Newton hareket denklemlerinin sayısal çözümü için tercih edilen algoritmalara bağlı olarak hesaplamalar sonucunda elde edilen değerler arasında makul sayılabilecek derecede farklılıklar ortaya çıkmaktadır.

Benzetimde örgü parametreleri, her bir potansiyel için $50 \mathrm{~K}$ 'den $3000 \mathrm{~K}$ 'e kadar $50 \mathrm{~K}$ aralıklarla hesaplandı. Belirlenen örgü parametre değerlerinin sıcaklığa bağlı değişimleri deneysel değerlerle[39] karşılaştırılmalı olarak Şekil 2'de gösterilmektedir. Şekilde veriler, kullanılan potansiyeller ile belirlenen en düşük erime sıcaklığına $(\sim 1670 \mathrm{~K})$ kadar gösterildi. Düşük sıcaklıklarda bütün MD benzetim sonuçlarından elde edilen örgü parametre değerleri hem bir birleriyle hem de deneysel değerlerle büyük ölçüde tutarlı görülmektedir. Beklendiği gibi, artan sıcaklıkla birlikte her biri doğrusal olarak artma eğiliminde fakat artışlar farklı eğim açıları ile gerçekleşmektedir. Diğer yandan, yüksek sıcaklıklarda hesaplanan değerler ile deneysel değerler arasında küçük sapmalar oluşmaktadır ve bu sapma miktarı özellikle SC çok cisim potansiyel sonuçlarında daha belirgin olarak ortaya çımaktadır. Fonksiyon olarak aynı forma sahip fakat farklı parametre değerleri olan Q-SC çok cisim potansiyeli, SC potansiyeline göre deneysel değerlere daha yakın sonuçlar üretmiştir. Bunun yanı sıra TB ve EAM2'den elde edilen sonuçlar Q-SC'e benzer değerler üretmektedir. Son olarak Sheng ve arkadaşları [23] tarafindan geliştirilen EAM1 çok cisim potansiyelinin ise diğer potansiyellerle karşılaştırılddı̆ında deneyselle en uyumlu sonuçları ürettiği açıkça görülmektedir. Bu sonuçlara göre, örgü parametresi için SC en yüksek ve EAM1 ise en düşük değerleri öngörürken, kullanılan potansiyellere göre örgü parametreleri arasında $a_{S C}>a_{E A M 2}>a_{T B}>a_{Q-S C}>a_{E A M I}$ ilişkisi olduğunu görülmüştür.

Doğrusal termal genleşme katsayısı (Coefficient of Linear Thermal Expansion (CLTE)), $\alpha$, malzemede sıcaklık artışıla meydana gelen birim şekil değişimi gözlemlenerek elde edilen bir katsayıdır. Yani bir birim sıcaklık değişiminde, maddede meydana gelen uzunluk değişimi gözlemlenerek elde edilir. Bu tanımdan yola çıkarak sistemin sıcaklığa bağlı CLTE'si

$$
\alpha=\frac{1}{L}\left(\frac{d L}{d T}\right)
$$

bağıntısı ile hesaplandı. Burada $\alpha$, doğrusal termal genleşme katsayısını ve $L$, MD hesaplama hücresinin boyunu temsil etmektedir.

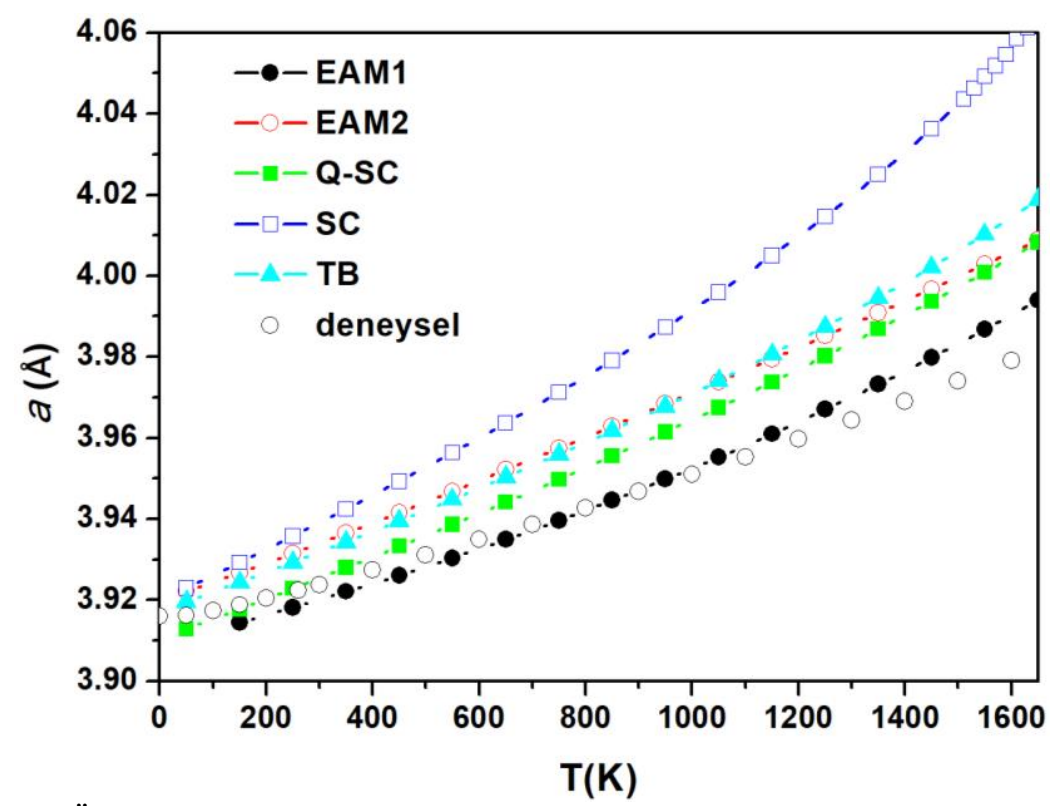

Şekil 2. Örgü parametresinin sıcaklıkla değişimi. Deneysel veri [39]'dan alınmıştır. 


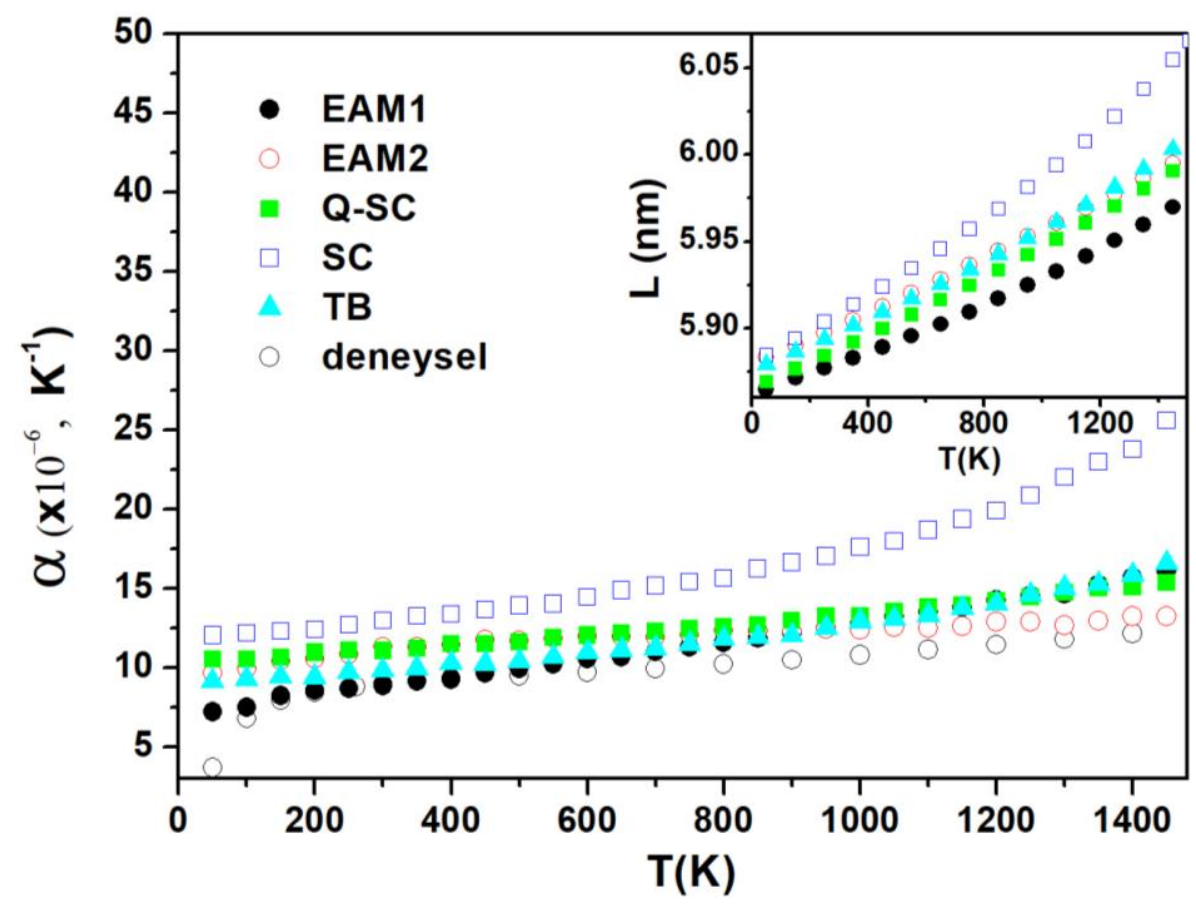

Şekil 3. Farklı potansiyeller için MD benzetimden hesaplanan ve deneysel CLTE’nin $(\alpha)$ sıcaklığa bağlı değişimi ve şeklin sağ üst köşesine gömülen grafik MD hesaplama hücre boyunun sıcaklıkla değişimini temsil eder.

MD benzetimle farklı potansiyeller için 50-1500 K arasında hesaplanan CLTE ve L'nin sıcaklığa bağlı değişimleri Şekil 3 'te ve bunun yanı sıra MD hesaplama hücresinin boyunun sıcaklığa bağlı değişimi ise şeklin sağ üst köşesinde gösterilmektedir. CLTE oldukça hassas bir değer olmasına rağmen benzetim analizlerinden elde ettiğimiz sonuçların birbirlerine yakın sonuçlar ürettiği ve özellikle EAM1, EAM2, Q-SC ve TB sonuçlarının deneyselle [39, 40] büyük oranda uyumlu olduğu söylenebilir. EAM1 çok cisim potansiyeli kullanılarak elde edilen sonuçların, özellikle düşük sıcaklıklarda, deneysel sonuçlarla iyi bir uyum sergilediği görülmektedir. Diğer yandan EAM2 sonuçlarının ise yüksek sıcaklıklarda deneysel değerlere daha yakın sonuçlar üretmektedir. Yukarıdaki bölümlerde farklı analizlerle tartışılan sonuçlara benzer bir şekilde SC potansiyelinden elde edilen değerlerin, kullanılan diğer potansiyellerden elden edilenlere göre deneysel değerlerden çok daha büyük olduğu görülebilmektedir. $300 \mathrm{~K}$ sicaklıkta $\mathrm{MD}$ benzetimden hesaplanan CLTE değerleri EAM1 için $\alpha=8,83 \times 10^{-6} \mathrm{~K}^{-1}$, EAM2 için $\alpha=11,31 \times 10^{-6} \mathrm{~K}^{-1}$, Q-SC için $\alpha=11,06 \times 10^{-6} \mathrm{~K}^{-1}$, SC için $\alpha=12,96 \times 10^{-6} \mathrm{~K}^{-1}$ ve TB fonksiyonu için ise $\alpha=9,83 \times 10^{-6} \mathrm{~K}^{-1}$ olarak belirlenmiştir. Elde edilen bu değerler deneysel CLTE, $\alpha=8,8 \times 10^{-6} \mathrm{~K}^{-1}(\sim 298.15 \mathrm{~K}$ için $)$ [41], değeri ile karşılaştırıldığında, bu değerlerden EAM1 için \% 0.34, EAM2 için \% 28.52, Q-SC için \% 25.68, SC için \% 47.27 ve TB için ise \% 11.70 oranında sapma olduğu görülmektedir. Yüksek sıcaklıklar için bu sapma miktarları potansiyellere göre farklılıklar gösterebilir. Üsteki bölümlerde bildirildiği gibi, bu analiz sonucunda da EAM1 ve TB potansiyellerinin diğer potansiyellere göre daha iyi sonuçlar ürettiği açıkça görülmektedir.

\section{2. Çiftler Dağılım Fonksiyonu ve Yapı Faktörü}

Çitler dağılım fonksiyonu (Pair Distribution Function (PDF)), $g(r)$, merkezdeki bir atomdan $r$ mesafe uzaklıkta bir başka atomun bulunma olasılığını temsil eder. PDF eğrileri, 1sıtma ve soğutma süreçlerinde faz geçişlerini belirlemek ve bunun yanı sıra katı, sıvı ve amorf sistemlerin yapısal özelliklerini karakterize etmek için sıklıkla kullanılır. MD benzetimde kullanılan $g(r)$ 'nin ifadesi;

$$
g(r)=\frac{V}{4 \pi r^{2} N^{2}}\left\langle\sum_{i} \sum_{i \neq j} \delta\left(r-r_{i j}\right)\right\rangle
$$


şeklinde verilir. Burada $N$ ve $V$ sırasıyla MD hesaplama hücresinde bulunan atomların sayısını ve hacmini temsil etmektedir.

Dört farklı potansiyel (EAM1, EAM2, SC ve TB) kullanılarak erime noktası civarında elde edilen PDF eğrileri Waseda [42] tarafindan üretilen deneysel $g(r)$ eğrileri ile karşılaştırmalı olarak Şekil 4 'te verilmektedir. Q-SC potansiyeli kullanılarak gerçekleştirilen MD benzetim çalışmasında sistem yüksek sıcaklıklarda $\left(\mathrm{T}_{\mathrm{m}}=2410 \pm 5 \mathrm{~K}\right)$ eridiği için deneysel değerle $(\sim 2053 \mathrm{~K}$ [42]) karşılaştırması yapılamamıştır. Bütün potansiyeller için PDF eğrilerinin ilk tepe noktalarının konumu deneyselle iyi bir uyum içindedir. EAM1 ve TB için ilk tepe noktalarının yükseklikleri deneysel PDF eğrisi ile aynı yüksekliğe sahipken, EAM2 ve SC için elde edilen PDF'lerin ilk tepe noktaları daha düşük tepeler üretmektedir. Her ne kadar, bütün PDF'lerin uzun menzildeki salınımlarının genlikleri deneysel $g(r)$ ile iyi bir uyum gösterse de, bunların içinde TB potansiyeli ile elde edilen $g(r)^{\prime}$ lerin salınım genliklerinin deneysel sonuçla çok daha iyi bir uyum sergilediği açıç̧a görülebilmektedir. Sonuç olarak, PDF açısından, bütün potansiyellerin platin elementi için başarılı sonuçlar ürettiği söylenebilir.

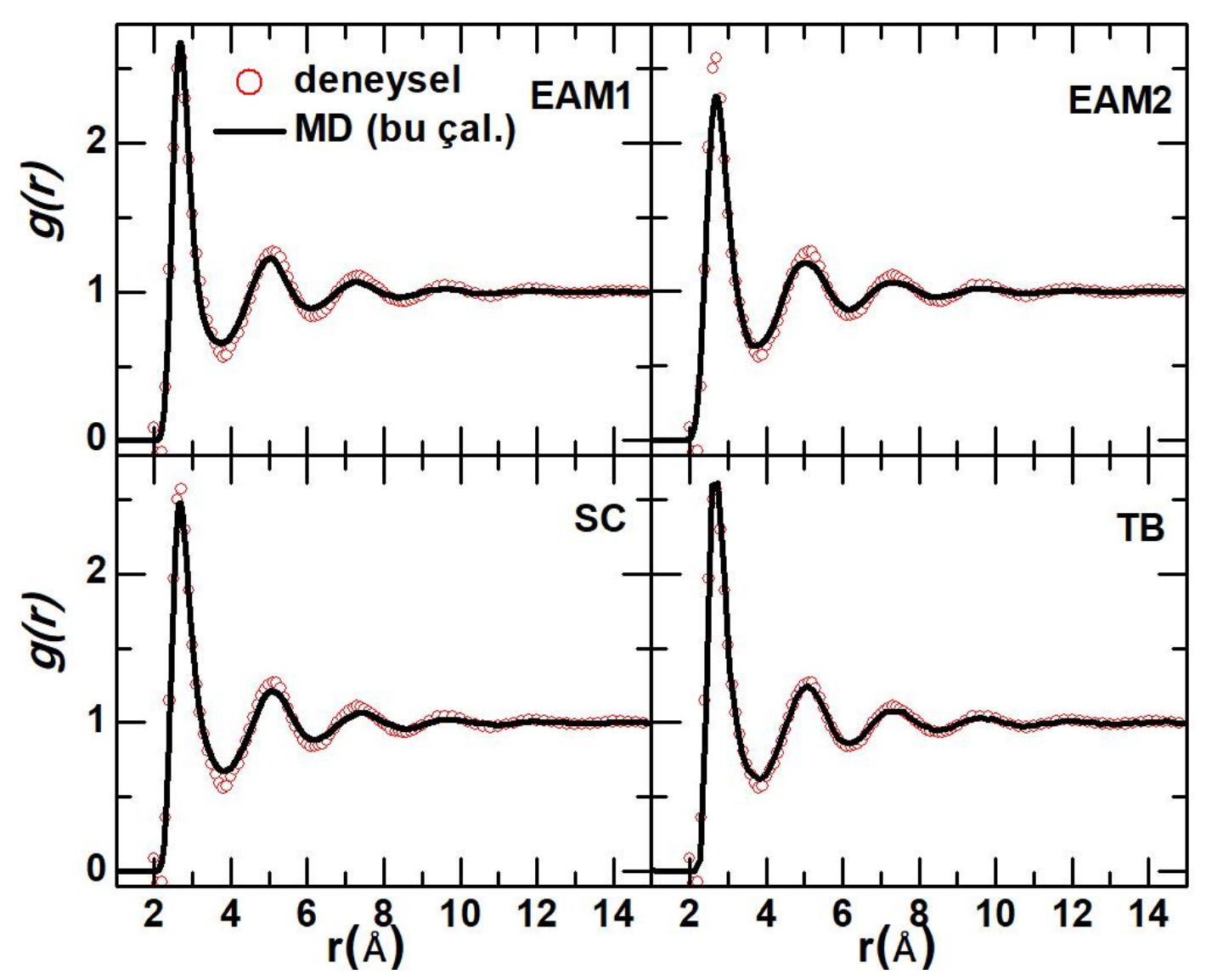

Şekil 4. EAM1 (2060 K), EAM2 (2050 K), SC (2050 K) ve TB (2050 K) çok cisim potansiyelleri için hesaplanan ve deneysel ( 2053 K [42]) sıvı $g(r)$ eğrileri. Bu sıcaklıkta Q-SC için sistem halen kristal formda olduğu için deneyselle karşılaştırma yapılamadı.

Farklı potansiyeller için farklı sıcaklıklarda $(300 \mathrm{~K}, 1000 \mathrm{~K}, 1500 \mathrm{~K}$ ve $2500 \mathrm{~K})$ elde edilen $g(r)$ eğrileri Şekil 5'te karşılaştırmalı olarak verilmektedir. $300 \mathrm{~K}$ 'de elde edilen $g(r)$ eğrileri küçük farklılıklar dışında bütün potansiyeller için $f c c$ kristal yapılara ait keskin pikler üretmektedir. Benzer şekilde $1000 \mathrm{~K}$ ve $1500 \mathrm{~K}$ deki $g(r)$ eğrilerinin de $f c c$ kristal yapıyı temsil eden pikler gösterdiği, fakat $300 \mathrm{~K}$ 'deki $g(r)$ piklerine nazaran daha alçak pikler ürettiği görülmektedir. Burada farklı potansiyeller için $g(r)$ eğrilerinde görülen küçük farkl1lıklar, büyük oranda bu potansiyellerin saf Pt'yi geniş ve farkl1 bir sıcaklık aralığında (1670-2410 K) eritmesiyle alakalıdır. Sıcaklığın daha da arttırılmasıyla birlikte, $g(r)$ eğrilerinin pik yükseklikleri azalmakta/yumuşamakta ve piklerin genliklerinde genişlemeler 
olmaktadır. Bütün potansiyeller için erime noktalarının üzerinde olan $2500 \mathrm{~K}$ sıcaklıkta ise $g(r)$ eğrileri sistemin sıvı olduğunu temsil eden davranış sergilemiştir. Yani, $g(r)$ 'lerin belirgin bir ilk tepe, görünür bir ikinci tepe ve belli bir özelliğe sahip olmayan kuyruğa sahip olması, bunun yanı sıra $g(r)$ 'nin tepe noktalarının genişlemesi ve ikinci tepe noktasından daha büyük bir mesafede güçlü tepe noktalarının olmayışı, sistemin artık kristal uzun menzil düzenini kaybettiğini ve nihai olarak eridiğini gösterir.

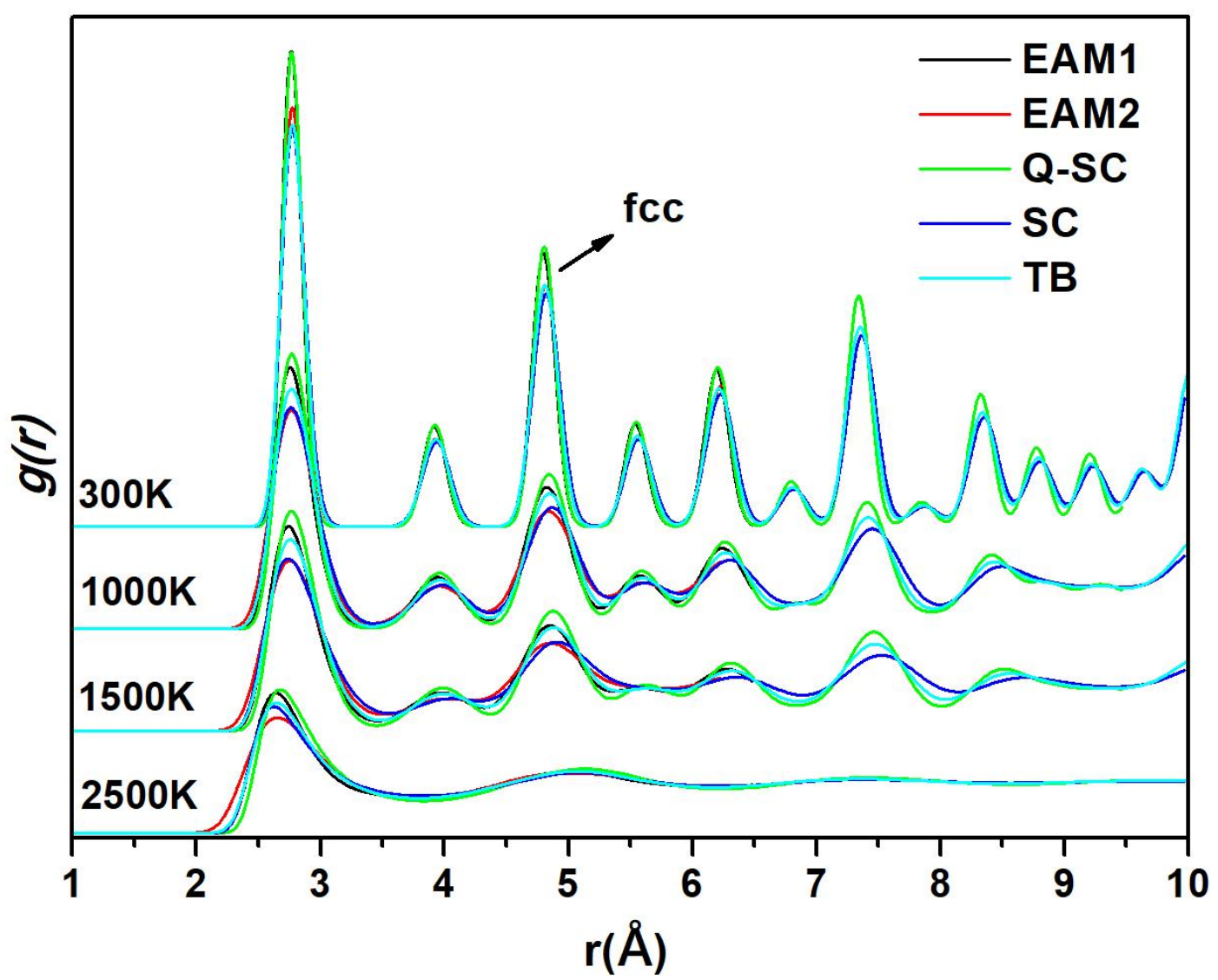

Şekil 5. Beş farklı potansiyel için $300 \mathrm{~K}, 1000 \mathrm{~K}, 1500 \mathrm{~K}$ ve $2500 \mathrm{~K}$ sıcaklıklarda elde edilen $g(r)$ eğrileri.

Isıtma ve soğutma süreçlerinde sistemdeki yapısal gelişimi gösteren diğer önemli bir yöntem ise sistemin yap1 faktörüdür (Structure Factor (SF)). SF, sistemdeki atomların uzaysal dağılımlarını karakterize eder ve uzaysal yapının bir görünümünü sağlar [26]. Yapı faktörü $S(q), g(r)$ 'nin Fourier dönüşümü olarak tanımlanır ve aşağıdaki formda verilir [42].

$$
S(q)=1+4 \pi \rho \int_{0}^{\infty} r^{2} \frac{\sin q r}{q r}(g(r)-1) d r .
$$

Burada $\rho$, sistemin ortalama sayı yoğunluğudur.

EAM1, EAM2, SC ve TB çok cisim potansiyelleri ile gerçekleştirilen MD benzetimleri sonucundan hesaplanan PDF'lerin Fourier dönüşümü yapılarak deneysel erime noktasının hemen üzerindeki sıcaklık için hesaplanan $S(q)$ eğrileri, deneysel verilerle [42] birlikte Şekil 6'da sunulmuştur. Bütün potansiyeller için hesaplanan $S(q)$ eğrileri sıvı sistemlere has tepe noktaları ve salımlar göstermektedir. Ayrıca, hesaplanan $S(q)$ eğrileri ile deneysel eğriler arasında oldukça iyi bir uyum gözlenmiştir. Bütün $S(q)^{\prime}$ ların ilk tepe noktalarının yüksekliklerinin deneyselden daha düşük olmasına rağmen bu tepelerin konumları deneysel sonuçlarla uyumludur. Dahası ikinci ve diğer piklerin yükseklikleri, konumları ve genlikleri deneysel sonuçlarla tutarlıdır. Bu sonuçlar, çalışmada kullanılan potansiyellerin sistemin yapısal özelliklerini açıklamada başarılı sonuçlar üretebildiğini ve sistemdeki atomik etkileşmeleri açıklamakta başarılı olduğunu göstermektedir. 


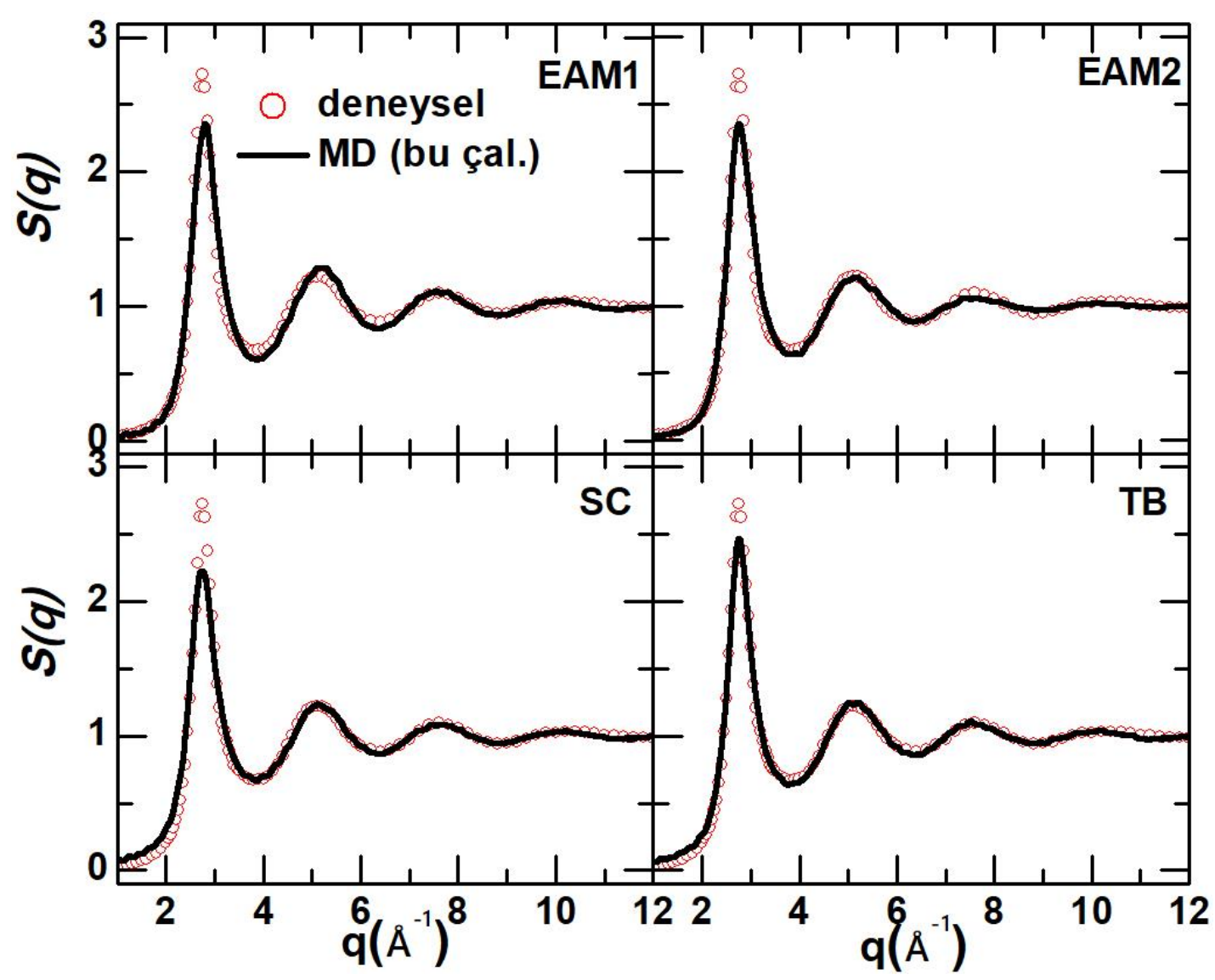

Şekil 6. EAM1 (2060 K), EAM2 (2050 K), SC (2050 K) ve TB (2050 K) çok cisim potansiyelleri için hesaplanan ve deneysel ( 2053 K [42]) sıvı $S(q)$ eğrileri. Bu sıcaklıkta Q-SC için sistem halen kristal formda olduğu için deneyselle karşılaştırma yapılamadı.

\section{3. Çiftler Analiz (Honeycutt-Andersen (HA)) Metodu}

Sistemin mikro yapısında neler olup bittiği hakkında daha ayrıntılı bilgi alabilmek için daha farklı analiz yöntemlere ihtiyaç duyulur. Komşu analizleri, atom konumlarından faydalanarak sistemde oluşan tüm desenleri istatistiki açıdan ele alan metotlardandır. Honeycutt - Andersen tarafından önerilen çift analizi (HA) [43] bu metotların başında gelir. Bu yöntem, Honeycutt-Andersen (HA) tarafindan tarif edildiği gibi katı, amorf ve sıvı sistemlerdeki atomik çiftlerin yerel çevresini tanımlamak için kullanılan oldukça faydalı ve açıklayıcı bir yöntemdir [5]. HA tekniğinde, çiftin yerel çevresini karakterize etmek için dört farklı tam sayıda oluşan indis dizisi, ijkl, kullanılır. İlk tam sayı $i$, verilen iki atomun bağlı olup olmadığını gösterir. Yani kök çiftleri bağlıysa ilk tamsayı $l$ olur, aksi halde 2 'dir. İkinci tam say $j$, kök çiftleriyle ortak olan yakın komşu atomların sayısıdır. Üçüncü tam sayı $k$, bu ortak noktalar arasındaki yakın komşu bağlarının sayısını verir. Dördüncü tam sayı $l$ ise, ilk üç tam sayı $(i, j, k)$ aynı olduğunda yerel yapıları ayırt etmek için kullanılan bir parametredir. HA tekniğine göre, 1431 ve 1541 bağlı çiftleri, kusurlu icosahedra (defect icosahedra) (deficos) ve kusurlu $f c c$ yapısının karakteristiğidir [44], 1551 bağlı çifti ise ideal icosahedra (icos) düzeninin karakteristiğidir. 1421 ve 1422 bağlı çiftleri ise yüzey merkezli kübik $(f c c)$ ve sıkı paketlenmiş altıgen $(h c p)$ kristal yapıların karakteristiğidir. 1661 ve 1441 bağlı çiftleri cisim merkezli kübik $(b c c)$ kristal yapının karakteristiğidir. Son olarak, 1321 ve 1311 bağlı çiftler, 1551 paketleme formları oluştuğunda ve icosahedra atomik paketlemenin yan ürünü olarak görülebilen eşkenar-dörtgen (rhombohedra) çiftleri ile ilgili paketlerdir. HA yöntemiyle ilgili daha ayrıntılı bilgi Ref $[5,43,45,46]^{`}$ dan alınabilir. Bahsi geçen bağlı çiftlerin şematik gösterimi Şekil 7'de verilmiştir. 


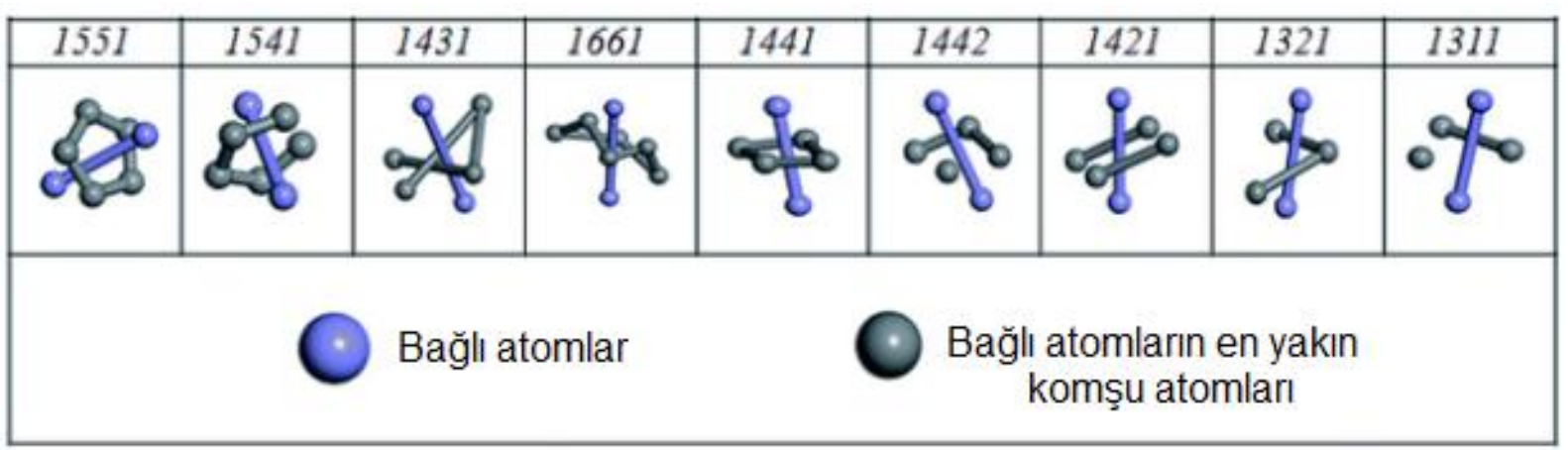

Şekil 7. Popüler bazı bağlı atom çiftlerinin şematik gösterimi [47].

Beş farklı potansiyel kullanılarak elde edilen verilerin HA yöntemi ile analizleri sonucunda, sistemde en yaygın halde bulunan 1421, 1422, 1661, 1441, 1551, 1541, 1431, 1311 ve 1321 bağl1 çiftlerinin sıcaklığa bağlı değişimleri Şekil 8'de sunulmuştur. Ayrıca bu şekil sistemin katı fazdan sıvı faza geçiş esnasındaki sıcaklığa bağlı mikro yapı değişikliklerini de temsil etmektedir. Şekil 8'de, düşük sıcaklıklarda 1421 bağlı çiftlerinin bulunma yüzdesi $\% 100$ olmuştur. 1421 bağl çiftleri $f c c$ yapıyı temsil ettiğinden, bu da sistemin $f c c$ kristal yapıda olduğunu gösterir. Artan sıcaklıkla bu çiftlerin yüzdesi azalmakta olup her bir potansiyel için erime noktası civarında keskin bir düşüş görülmektedir ve neredeyse $\% 0$ civarına düşmektedir. Keskin düşüşün gerçekleştiği sıcaklık sistemin katı fazdan sıvı faza geçişin gerçekleştiği erime noktasına karşılık gelir. 1421 bağl çiftlerindeki azalmaya karşılık özellikle 1431 ve 1541 bağlı çiftlerinin yüzdesinde sistemin erime sıcaklığına kadar sürekli bir artış gözlenmektedir. Bu artış erime sıcaklığında 1541 bağlı çiftleri için tüm potansiyeller için ortalama \% 20 civarında iken 1431 bağlı çiftleri için bu oran \% 25 civarındadır. Diğer taraftan $b c c$ kristal yapıyı temsil eden 1441 ve 1661 bağlı çiftlerinde, hcp yapıyı temsil eden 1422 bağlı çiftinde, icos tipi temsil eden 1551 bağlı çiftinde ve rhombohedra düzeni temsil eden 1311 bağl çiftinde de 1431 ve 1541 bağlı çiftlerine göre daha az oranda fakat sürekli bir artış görülmektedir. Bu sonuçlar, 1sıttma sürecinde mono atomik Pt sisteminin yapısında önemli değişimlerin olduğunu, diğer bir deyişle, sistemin doğal yapısını temsil eden 1421 bağlı çiftlerinin, artan sıcaklıkla birlikte özellikle deficos ve kusurlu fcc yapıları temsil eden 1431 ve 1541 bağlı çiftlerine ve diğer bağlı çiftlere dönüştüğünü gösterir. Sıvı sistemde bütün potansiyeller için 1321 ve 1311 bağlı çiftlerin sayısının artan sıcaklıkla birlikte yüzdeleri artarken, 1422 ve 1431 bağlı çiftleri neredeyse sıcaklığa karşı duyarsız kalmaktadır. 1661, 1441, 1551 ve 1541 bağlı çiftlerinin oranında erime sıcaklığı civarında önce keskin azalma görülürken, daha sonra, ya sabit kalmakta ya da çok az miktarda sıcaklığa bağlı değişim göstermektedir. Sonuç olarak, bu çalışmada seçilen EAM1, EAM2, Q-SC, SC ve TB çok cisim potansiyelleri, MD benzetim sonuçlarının HA yöntemiyle analizi açısından birbirlerine benzer davranış sergilemiştir. Genel hatlarıyla bütün potansiyellerin bazı farklılıkları olmasına rağmen sistemin mikro yapısının sıcaklığa bağlı değişimini başarılı bir şekilde açıklayabildikleri ve büyük oranda atomlar-arası etkileşmeleri doğru bir şekilde tanımlayabildikleri sonucuna varılmıştır. 


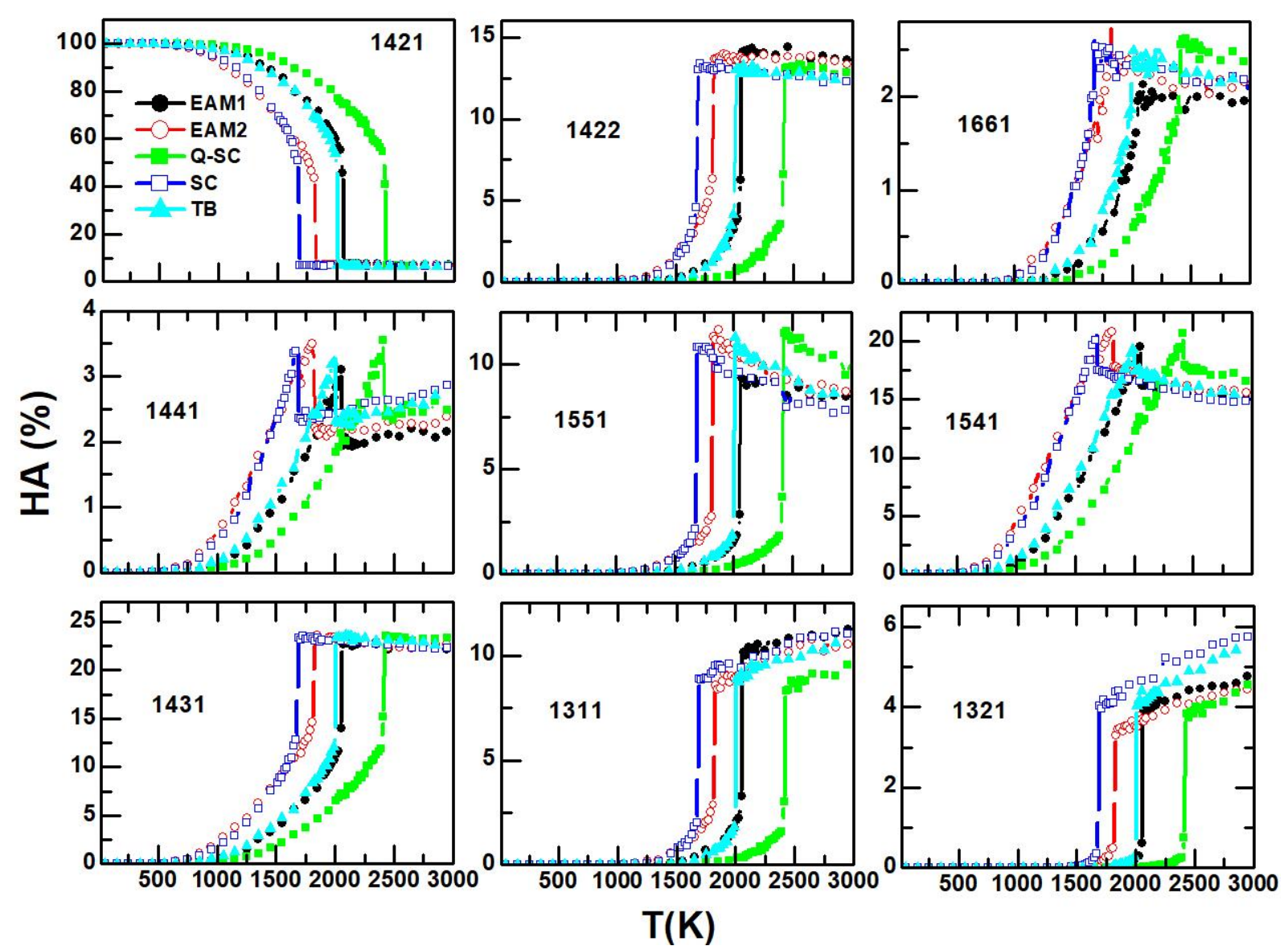

Şekil 8. Farklı potansiyellerin analizinden sistemde baskın olarak bulunan bazı kümelerin sıcaklığın fonksiyonu olarak değişimi.

\section{Sonuç ve Tartışma}

Bu çalışmada $f c c$ yapıya sahip Pt elementinin ısıtma işlemi sırasında MD benzetim metodu yardımı ile yapısal gelişimi ve erime noktası gibi bazı fiziksel özellikleri üzerine potansiyel etkisini araştırmak için çok cisim potansiyel ailesinden olan EAM1, EAM2, Q-SC, SC ve TB potansiyelleri kullanılmıştır. Seçilen çok cisim potansiyellerinin mono atomik katı Pt sistemini farklı sıcaklıklarda erittiği görülmüştür. Bu potansiyeller arasında sistemin, özellikle EAM1 ve TB çok cisim potansiyelleri kullanılarak belirlenen, erime noktası deneysel değer ile iyi bir uyum göstermektedir. Diğer yandan tüm potansiyeller için örgü parametresi ve doğrusal genleşme katsayısı gibi fiziksel özellikler alan yazında sunulan deneysel sonuçlarla büyük ölçüde tutarlı görünmesine rağmen, bunların içinde EAM1, EAM2, Q-SC ve TB potansiyellerinin çok daha başarılı sonuçlar ürettiği görülmüştür. Sistemin sıcaklığa bağlı yapısal gelişimini araştırmak için PDF ve SF kullanılmıştır. EAM1, EAM2, SC ve TB çok cisim potansiyelleri kullanılarak $\sim 2050 \mathrm{~K}$ civarında elde edilen PDF ve SF eğrileri deneysel $g(r)$ ve $S(q)$ eğrileri ile tutarlı sonuçlar üretmiştir. Katı sistemin sıcaklığa bağlı olarak mikro yapısındaki değişmeleri incelemek için HA analiz yöntemi kullanılmıştır. Elde edilen sonuçlar $f c c$ kristal yapıyı temsil eden 1421 bağlı çiftlerinin artan sıcaklıkla azaldığını ve özellikle bu çiftlerin kusurlu icosahedra ve kusurlu $f c c$ yapıyı temsil eden 1541 ve 1431 bağlı çiftlerine dönüştüğünü göstermiştir. Sonuç olarak, klasik MD benzetimlerinde atomlar-arası potansiyellerin seçiminin ele alınan sistemin hangi özelliklerinin hesaplanacağına ve bu özelliklerin hangi sıcaklık aralığında ele alınacağına kuvvetli derecede bağlı olduğu ve genel olarak bütün potansiyellerin Pt sisteminin yapısal özelliklerini açıklamada büyük ölçüde başarı sağlamış olsa da, bunların içinde EAM1 ve TB çok cisim potansiyellerinin bu çalışmada araştırılan fiziksel özellikleri hem yüksek hem de alçak sıcaklıklarda doğru bir şekilde açıklamada diğer potansiyellere göre daha başarılı olduğu görülmüştür. 


\section{Kaynaklar}

[1] Sheng H.W., Luo W.K., Alamgir F.M., Bai J.M., Ma E. 2006. Atomic packing and short-tomedium-range order in metallic glasses. Nature, 439 (7075): 419-425.

[2] Zhou X.W., Johnson R.A., Wadley H.N.G. 2004. Misfit-energy-increasing dislocations in vapordeposited CoFe/NiFe multilayers. Physical Review B, 69 (14): 144113.

[3] Celik F.A. 2014. Molecular dynamics simulation of polyhedron analysis of $\mathrm{Cu}-\mathrm{Ag}$ alloy under rapid quenching conditions. Physics Letters A, 378 (30-31): 2151-2156.

[4] Domekeli U., Sengul S., Celtek M., Canan C. 2018. The melting mechanism in binary Pd0.25Ni0.75 nanoparticles: molecular dynamics simulations. Philosophical Magazine, 98 (5): 371-387.

[5] Sengul S., Celtek M., Domekeli U. 2017. Molecular dynamics simulations of glass formation and atomic structures in Zr60Cu20Fe20 ternary bulk metallic alloy. Vacuum, 136: 20-27.

[6] Zhang Y., Mattern N., Eckert J. 2011. Atomic structure and transport properties of Cu50Zr45Al5 metallic liquids and glasses: Molecular dynamics simulations, Journal of Applied Physics, 110 (9): 093506.

[7] Sengul S., Celtek M. 2018. Pressure Effects on the Structural Evolution of Monatomic Metallic Liquid Hafnium. BEU Journal of Science, 7 (1): 144-158.

[8] Johnson M.L., Blodgett M.E.E., Lokshin K.A.A., Mauro N.A.A., Neuefeind J., Pueblo C., Kelton K.F.F. 2016. Measurements of structural and chemical order in Zr80Pt20 and Zr77Rh23 liquids. Physical Review B, 93: 054203.

[9] Oluwajobi A., Chen X. 2011. The effect of interatomic potentials on the molecular dynamics simulation of nanometric machining. International Journal of Automation and Computing, 8 (3): 326-332.

[10] Allen M.P., Tildesley D.J. 1991. Computer simulation of liquids. Oxford,: Clarendon Press, NY, USA.

[11] Frenkel D., Smit B. 2002. Understanding molecular simulation: from algorithms to applications (Academic P.). San Diego, second edition.

[12] Brenner D.W. 2005. The Art and Science of an Analytic Potential,In Computer Simulation of Materials at Atomic Level. Weinheim, FRG: Wiley-VCH Verlag GmbH Co. KGaA, pp. 23-40.

[13] Jones J.E., Ingham A.E. 1925. On the calculation of certain crystal potential constants, and on the cubic crystal of least potential energy. Proc. R. Soc. London Ser. A, 107: 363.

[14] Morse P.M. 1929. Diatomic Molecules According to the Wave Mechanics. II. Vibrational Levels. Physical Review, 34 (1): 57-64.

[15] Daw M.S., Baskes M.I. 1984. Embedded atom method: derivation and application to impurities,surfaces and other defects in metal, Phsical Review B, 29 (12): 6443-6453.

[16] Daw M.S., Baskes M.I. 1983. Semiempirical, Quantum Mechanical Calculation of Hydrogen Embrittlement in Metals. Physical Review Letters, 50 (17): 1285-1288.

[17] Finnis M.W., Sinclair J.E. 1984. A simple empirical N -body potential for transition metals. Philosophical Magazine A, 50 (1): 45-55.

[18] Sutton A.P., Chen J. 1990. Long-range Finnis-Sinclair potentials. Philosophical Magazine Letters, 61 (3): 139-146.

[19] Rafii-Tabar H., Sutton A.P. 1991. Long-range Finnis-Sinclair potentials for f.c.c. metallic alloys. Philosophical Magazine Letters, 63 (4): 217-224.

[20] Jacobsen K.W., Norskov J.K., Puska M.J. 1987. Interatomic interactions in the effective-medium theory. Physical Review B, 35 (14): 7423-7442.

[21] Cleri F., Rosato V. 1993. Tight-binding potentials for transition metals and alloys. Physical Review B, 48 (1): 22-33.

[22] Rosato V., Guillope M., Legrand B. 1989. Thermodynamical and structural properties of f.c.c. transition metals using a simple tight-binding model. Philosophical Magazine A, 59 (2): 321336.

[23] Sheng H.W., Kramer M.J., Cadien A., Fujita T., Chen M.W. 2011. Highly optimized embeddedatom-method potentials for fourteen FCC metals. Physical Review B - Condensed Matter and Materials Physics, 83 (13): 1-20.

[24] Erkoç Ş. 1997. Empirical many-body potential energy functions used in computer simulations 
of condensed matter properties. Physics Reports, 278 (2): 79-105.

[25] Dömekeli Ü. 2011. Nanomateryallerin erime sürecindeki fiziksel özelliklerinin moleküler dinamik simülasyonu ile incelenmesi, Trakya Üniversitesi, Fen Bilimleri Enstitüsü, Doktora tezi, 243s, Edirne.

[26] Celtek M., Sengul S. 2019. Effects of the cooling rate on the atomic structure and the glass formation process of Co90Zr10 metallic glass investigated by molecular dynamics simulations. Turkish Journal of Physics, 43: 11-25.

[27] Cagin T., Qi Y., Li H., Kimura Y., Ikeda H., Johnson W.L., Goddard W.A. 1999. The Quantum Sutton-Chen Many-Body Potential for Properties of fcc Metals.MRS Symp. Ser., 554: 43.

[28] Qi Y., Cagin T., Kimura Y., Goddard III W.A. 1991. Molecular-dynamics simulations of glass formation and crystallization in binary liquid metals: $\mathrm{Cu}-\mathrm{Ag}$ and $\mathrm{Cu}-\mathrm{Ni}$. Phys. Rev. B, 59 (5): $3527-3533$.

[29] Kazanc S. 2006. Molecular dynamics study of pressure effect on glass formation and the crystallization in liquid CuNi alloy, Computational Materials Science, 38 (2): 405-409.

[30] Kart H.H., Tomak M., Uludoğan M., Çağın, T. 2005. Thermodynamical and mechanical properties of Pd-Ag alloys. Computational Materials Science, 32 (1): 107-117.

[31] Celik F.A. 2013. Cooling rate dependence of the icosahedral order of amorphous CuNi alloy: A molecular dynamics simulation. Vacuum, 97: 30-35.

[32] Celtek M., Sengul S., Domekeli U., Canan C. 2016. Molecular dynamics study of structure and glass forming ability of Zr70Pd30 alloy. European Physical Journal B, 89 (3): 65.

[33] Celtek M., Sengul S., Domekeli U. 2017. Glass formation and structural properties of Zr50Cu50xAlx bulk metallic glasses investigated by molecular dynamics simulations. Intermetallics, 84 : 62-73.

[34] Celtek M. 2011. Çok bileşenli $\mathrm{Cu}$ ve $\mathrm{Zr}$ bazlı bulk metalik camsı alaşımlarının fiziksel özelliklerinin MD simülasyon metodu ile incelenmesi, Trakya Üniversitesi, Fen Bilimleri Enstitüsü, Doktora tezi, 229s, Edirne.

[35] Celtek M., Sengul S. 2018. The characterisation of atomic structure and glass-forming ability of the $\mathrm{Zr}-\mathrm{Cu}-\mathrm{Co}$ metallic glasses studied by molecular dynamics simulations. Philosophical Magazine, 98 (9): 783-802.

[36] Kittel C. 1986. Introduction to Solid State Physics, New York: John Wiley Sons Inc, USA.

[37] Smith W., Forester T.R. 1996. DL_POLY_2.0: A general-purpose parallel molecular dynamics simulation package. Journal of Molecular Graphics, 14 (3): 136-141.

[38] Nosé S. 1984. A unified formulation of the constant temperature molecular dynamics methods. The Journal of Chemical Physics, 81 (1): 511-519.

[39] Arblaster J.W. 1997. Crystallographic Properties of Platinum. Platinum Metals Rev., 41 (1): 1221.

[40] Kirby R.K. 1991. Platinum-A Thermal Expansion Reference Material. International Journal of Thermophysics, 12 (4): 679-685.

[41] Cohen E.R., Cohen R.E., Lide D., Trigg G. 2003. Physicist's Desk Reference, Springer.

[42] Waseda Y. 1981. The Structure of Non-Crystalline Materials-Liquids and Amorphous Solids. New York: London: McGraw-Hill, USA.

[43] Honeycutt J.D., Andersen H.C. 1987. Molecular Dynamics Study of Melting and Freezing of Small Lennard- Jones Clusters. Journal of Physical Chemistry, 91 (24): 4950-4963.

[44] Li G.X., Liang Y.F., Zhu Z.G., Liu C.S. 2003. Microstructural analysis of the radial distribution function for liquid and amorphous Al. Journal of Physics: Condensed Matter, 15 (14): 22592267.

[45] Çelik F.A., Kazanç S. 2010. CuNi Alaşımının Amorf Fazdan Kristal Faza Dönüşüm Sürecinde Mikro-Topak Özelliklerinin Moleküler Dinamik Yöntem ile İncelenmesi. Fırat Üniv. Fen Bilimleri Dergisi, 22 (2): 79-84.

[46] Çelik F.A. 2010. Geçiş Metali Alaşımlarında Amorf Yapıdan Kristal Yapıya Dönüşümün Moleküler Dinamik Yöntemi ile İncelenmesi, Fırat Üniversitesi, Fen Bilimleri Enstitüsü, Doktora tezi, 177s, Elazı ğ.

[47] Chen H.-L., Su C.-H., Ju S.-P., Liu S.-H., Chen H.-T. 2015. Local structural evolution of Fe 54 C $18 \mathrm{Cr} 16$ Mo 12 bulk metallic glass during tensile deformation and a temperature elevation process: a molecular dynamics study. RSC Advances, 5 (126): 103925-103935. 